\title{
Books on Religion in State University Libraries
}

\begin{abstract}
Despite the desirability of keeping Church and State apart, books on religion do have an appropriate place in state university libraries. Such book selection policies as exist for tax-supported institutions allow the selection of religious books, many to meet the curricular and research needs of related subjects, or to accommodate peculiar local requirements, but others may be justified on their own merits. The same criteria of selection should be applied to books on religion as to books on other subjects.
\end{abstract}

$T_{1}$ HE CONSTITUTIONAL PROVISION for the separation of church and state in the United States has caused the responsibility for the teaching of religion to rest mainly with private educational institutions. Yet, a dichotomy between the study of religion and other areas of human concern is virtually impossible to imagine even in a secular academic community. Recognizing the potential controversy which exists in this situation, as well as the need to support all areas of knowledge, the question comes to mind, "What factors bearing upon the book selection policy of a state university library might make possible or even encourage acquisitions in the field of religion?"

At least one major state-supported institution selecting religious books is the University of California. A brief survey of the library holdings on the Berkeley campus shows that there is a sizable collection of materials in the classification's BL-BX section for religion, and that in addition, the catalog contains an impres-

$\mathrm{Mr}$. Peterson is Librarian of Pacific Lutheran Theological Seminary, Berkeley, California. sive number of scholarly journals and serial publications. The library appears to have sufficient strength to support serious research in this field. Considering, however, that there is no department of religion at the University of California it might further be asked, "What has caused California to have a strong collection of religious literature?"

The premise of this study is that books on religion do have a place in the library of a state university. This is so for a number of reasons.

First, religion is an important area of human knowledge; it provides an extensive body of literature which is indispensable for understanding the moral and intellectual development of mankind. The place of theology as a scholastic discipline cannot be disregarded when one considers the impact of the Judeo-Christian tradition on the development of Western civilization, or the influence of the religions of Asia upon the culture of the East.

Second, religious knowledge cannot be separated and kept isolated from other subject fields such as music and the arts, philosophy and ethics, literature, history, 
sociology, and psychology. Could the development of Gothic architecture be understood apart from the religious influences of the medieval world? Could a study of colonial America ignore the theology of the Puritans? Can a concept of Japanese family life be grasped apart from some knowledge of Shintoism and its influence on the culture of that nation?

Third, one of the important functions of the university is to conserve knowledge, which presupposes its collection: Can any institution, whether privately endowed or state supported, be true to this responsibility if it neglects an area of knowledge as broad and pervasive as that of religion?

Finally, a university exists to serve the general educational needs and cultural interests of many people with a variety of backgrounds and purposes. While it may not use its position to foster any single or narrow sectarian bias, the library as a service agency should strive to meet the honest demands of its users for accurate and objective information in the area of religion as well as in any other subject field.

The objectives of this paper are fourfold: (1) to consider factors relevant to the selection of religious materials for a state university library; (2) to determine what kinds of literature may legitimately be collected; (3) to decide who should be involved in the selection process; and (4) to provide first-hand data regarding the attitudes and practices of faculty members in the selection of religious books.

An examination of the literature of librarianship shows that comparatively little has been written on this subject. An article by Nils H. Sonne, "Principles for the Selection of Religious Books,"1 provides some specific information; but the author's point of view reflects his primary

\footnotetext{
1 Nils H. Sonne, "Principles for the Selection of Religious Books," Library Journal, LXXXIII (January 1958), 123-28.
}

concern with book selection for the theological library. The Humanities and the Library, by Lester Asheim and associates, ${ }^{2}$ is the most comprehensive treatment of religious materials and their selection; the focus of this work, however, is primarily on the public rather than the university library. Both the volumes by Helen E. Haines ${ }^{3}$ and by Carter and Bonk $^{4}$ include information on the selection of religious books; while the points of view in each of these are also directed primarily toward the public rather than the state university library, they do offer helpful general insights on the subject.

Although the general literature pertaining to book selection for university libraries does not deal individually with religious materials, it does offer a framework of general information and ideas within which a philosophy for selecting religious books may be conceived. Especially useful among the articles are those by Harry Bach, ${ }^{5}$ H. H. Fussler, ${ }^{6}$ Lawrence S. Thompson, ${ }^{7}$ A. V. Thakore, ${ }^{8}$ and Verner W. Clapp. ${ }^{9}$ In the same category are the chapters pertaining to book selection in the texts by Wilson and Tauber, ${ }^{10}$ and Tauber, ${ }^{11}$ the fuller treatment

\footnotetext{
2 Lester Asheim and associates, The Humanities and the Library; Problems in the Interpretation, Evaluation, and Use of Library Materials (Chicago, ALA, 1957), pp. 1-60.

${ }^{3}$ Helen E. Haines, Living with Books; the Art of Book Selection (2d ed.; New York: Columbia University Press, 1950), pp. 385-99.

4 Mary Duncan Carter and Wallace John Bonk, Building Library Collections (New York: Scarecrow Press, 1959), pp. 93-96.

"Harry Bach, "Acquisition Policy in the American Academic Library," CRL, XVIII (November 1957), 441-51.

Herman H. Fussler, "Problems of Acquisition Policy in a University Library," $C R L$, XIV (Oetober 1953), 363-67.

Tawrence S. Thompson, "The Dogma of Book Selection in University Libraries," CRL, XXI (November 1960), 441-45.

${ }^{8}$ Aroon V. Thakore, "The Practice of Book Selection in a University Library," Indian Librarian, XIV (September 1960), 71-75.

Verner W. Clapp, "Present Problem in Book Selection: Large Research Library," ALA : Intellectual Freedom Committee, Freedom to Communicate (Chicago: ALA, 1954), pp. 38-43.

${ }^{10}$ Louis Round Wilson and Maurice F. Tauber, The University Library (2d ed. : New York: Columbia University Press, 1956), pp. 346-93.

11 Maurice F. Tauber and associates, Technical Services in Libraries (New York: Columbia University Press, 1953), pp. 22-60.
} 
in the thesis by Henderson ${ }^{12}$ and the monograph by Danton. ${ }^{13}$ Finally, the acquisition policy statements of a number of state university libraries give some further information on the subject. While of the ones consulted for this study religion is specifically referred to only in those of Illinois, Louisiana, and Cornell among the state supported institutions, ${ }^{14}$ the principles enumerated by the statements in general allow through inference for a policy to be developed on the selection of religious books.

\section{Factors Relevant to the Selection of Religious Materials for a State UNIVERSITY LIBRARY}

Whether or not a university library has a written acquisition policy, certain factors are present in each individual institution which influence the decisions on which books will be selected. In order to develop the collection with some degree of consistency and purpose, these factors need to be recognized. Because much religious literature is of a polemical nature and may be considered highly controversial, its selection or rejection must especially be based on objective facts.

The first factor to consider is the nature of the university's program of instruction and research. While it is generally the case that religion as such is not taught in tax-supported institutions, it should be noted that out of forty-six state universities checked, eight list individual departments of religion, one lists a department of philosophy and religion, and another a department of

\footnotetext{
12 William T. Henderson, "Acquisition Policies of Academic and Research Libraries," Master's thesis (Chicago: Graduate Library School, University of Chicago, 1960), 193p. Microfilm.

${ }^{13} \mathrm{~J}$. Periam Danton, Book Selection and Collections: A Comparison of German and American University Libraries (New York: Columbia University Press, 1963), 188p.

14 University of Illinois, Acquisition Policy Statement (Urbana: February 1959), 13p. Mimeograph. Louisiana State University and Agricultural and Mechanical College, Book Selection Policies and Procedures (Baton Rouge, 1953), 6p. Mimeograph. Cornell University, Outline of an Acquisition Policy (April 1953), 4p. Mimeograph.
}

Bible. ${ }^{15}$ Even at the University of California, which does not support a separate department of religion, a number of courses are given within the departments of history, literature, philosophy, and sociology which deal in large part with religious knowledge. ${ }^{16}$ Also to be considered in this area are the special strengths of faculty members in subjects related to religion. In his 1962-63 report, the librarian at UCLA writes, "In anticipation of the forthcoming appointment to the history department of a specialist in church history, especially of the Renaissance, we began a planned program to purchase fundamental journals and texts in theology and church history, such basic works as the Revue des sciences ecclésiastiques, Nouvelle revue theologique, and Collectanea Franciscana."17 In addition, a number of courses offered in departments such as those mentioned above are involved with the study of religion as it is interrelated with a wide range of subject fields. Thus, since the library's function is to provide resources to support all areas of instruction and research, religious books must be selected to meet the needs of this subject ade-

15 See Mary Irwin, ed., American Universities and Colleges ( 8 th ed.; Washington, D.C.: American Couneil on Education, 1960), 1212p. Departments of religion are listed for the Universities of Florida, Georgia, Hawaii, Iowa, Montana, North Carolina, Oregon, and Virginia; the University of Vermont lists a department of philosophy and religion, and the University of South Dakota a department of Bible.

16 University of California (Berkeley), General Catalogue, 1963/64 (Berkeley: University of California, 1963), 613p. The following list indicates those courses from the eatalog which deal directly with religious studies: Anthropology 124: "Primitive Religion"; Art 275: "Seminar in the History of Early Christian and Medieval Art"; Classies 176: "Ancient Greek Religion"; English 116: "The English Bible as Literature"; History 132: "The Age of Reformation"; Near Eastern Languages 152: "Religion and Cult in Ancient Palestine"; 161A-161B: "The Religions of Ancient Iran"; 170: "Religion and Cosmology of Ancient Mesopotamia," 181: "Islamic Institutions," 111A-111B: "Biblical Hebrew Texts," 211A-211B: "Advanced Biblical Hebrew"; Phiłosophy 112: "Philosophy of Religion"; Slavic Languages and Literature 151: "The Reformation and CounterReformation in Polish Literature"; Sociology 146: "Sociology of Religion," 147: "Religious Doctrines and Social Conduct," and 246: "Sociology of Religion" (Seminar).

${ }^{17}$ Robert Vosper, Report of the University Librarian to the Chancellor for the Year 1962/63 (Los Angeles: University of California), p.3. 
quately within the curriculum. In this regard, the level of collecting, which will be discussed more fully in the next section, should generally be in direct ratio to the extent of instruction and research in the university's program.

A second factor bearing upon the selection of religious books may be the university's responsibility to collect materials related to the history of the community or state in which it is located. If religious forces have had an important influence on the region's culture or heritage, the literature in support of this cannot be overlooked. Two illustrations may be hypothesized to provide examples. No attempt to understand the history or sociology of Utah could ignore the influence of the Mormons upon its development. Would it not be the obligation of a research library in that state, whether tax-supported or not, to amass as exhaustive a collection of materials as possible on Mormonism? No study of the early history of California can overlook the important role of the Spanish missions. Is it not in order for extensive holdings on this subject, which would also include supporting materials on Roman Catholicism, to be accumulated in a major research library of this state? The term "supporting materials" used above is not to be regarded lightly, for in each of these illustrations it is conceivable that works on doctrine, worship, evangelism, and other topics pertinent to these religions should be included. It is important, of course, for a university to decide the extent of its obligation to the history and culture of its area, and to support only those subjects which clearly have major significance in terms of the conservation of knowledge. The selection of fields to be covered must rise above the level of narrow sectarian interests.

Two additional factors closely associated with the foregoing are the nature of the existing collection and the relation of the library to other resources of the area. With regard to the nature of the collection there is a double responsibility. The first is that the university should seek to develop a balanced collection to the extent that there are no areas of intellectual or cultural significance in which materials of a general or reference nature are completely lacking; this would include books on religion as well as other subject fields. To neglect appreciably the selection of religious items would not only be an injustice to this area of human knowledge but would also be detrimental by its implications to the over-all strength and character of the library. Moreover, the university does have an obligation to maintain any special strengths its library already has. This includes adding new materials whenever they are available, and providing adequate supporting materials as mentioned previously. If a strong collection exists in an area related to religion, this would necessitate the continuous selection of religious books either as primary or secondary resources. The degree to which this would be done should, of course, logically depend upon the strengths or weaknesses of other libraries in the same region-which is the fourth factor to consider.

Libraries in close geographical proximity to each other should not compete in extensively collecting research materials of closely related fields. This is especially true in an area where a particular collection is being developed primarily to fulfill a sense of obligation to the community rather than to support the curriculum of the institution.

A fifth factor affecting the selection of religious books revolves around the extent to which the university offers service to the public at large, and the demands which the interests of this wider segment of users make upon the library. In discussing the concept of public service, Taube states, "A great university library usually serves more than the limited group of students or faculty members officially connected with the university 
of which it is a part."18 The degree to which a library will be affected by this concern will depend upon the policies of the university regarding the extent of its service beyond the needs of its own students and faculty members and the obligation to support its curriculum. It is conceivable in cases where a university policy requires service to the public at large that the requests of citizens for religious literature could be great and varied. Here, naturally, the university would have to decide the extent to which it should go in meeting these demands. Again, the resources of the area would have to be appraised-not only in terms of what the public libraries would offer, but also for what is available in the collections of local individual religious institutions. It would be imperative, for the sake of the university's academic integrity, that standards of quality be carefully observed in the selection of religious books to meet such demands. Even in the effort to serve the public, it is not within the scope of the university's responsibility to maintain anything corresponding to the Sunday school library of former years.

A final factor which cannot be overlooked is finances. Where there is a separate department of religion, it may be assumed following the commonly prevailing practices that it will receive an allocation from the budget for religious books. Where no such department exists one might expect that some religious materials would be selected by other departments, especially in the humanities and social sciences. Any other acquisitions would logically be charged to either a general fund or any special funds which may have been established for this purpose. The important concern is that adequate financial provisions are made for the purchase of religious books so that the university library can fulfill its responsibilities in this subject field.

1s Mortimer Taube, "Libraries and Research," CRL, II (December, 1940), 22-6.

\section{KindS OF Literature that MaY LegtTimately Be Selected}

The phrase "kinds of literature" presupposed for purposes of this paper three areas of consideration: qualitative standards, varieties of literary materials, and levels of collection.

Qualitative standards must be used by a university library in the selection of all literature; in this regard, religious books should not be an exception. In general, it is fair to expect that such materials should be highly accurate in the presentation of facts and of worthy scholarly value; they should be the equals in this respect of materials chosen in other subject fields. It is conceivable, of course, that some materials of an unscholarly nature may be acquired; when this is so, it should usually occur because these are the only items available on a particular subject, or because they have value for the specific ideas or views which they represent, or because they are needed for undergraduate instruction. As far as possible, the selection of literature should represent a balanced point of view with regard to any one religious idea, doctrine, or heritage. While it is not always possible to have all sides of a question presented in one book, considerable care should be exercised that books representing various points of view on a certain subject are acquired if they are available. In short, it should be the policy of the university in what it selects to maintain a respectable position for itself as an educational institution dedicated to the spread of knowledge through the quest for truth.

The variety of literary materials is as broad in the field of religion as in any other subject. Of primary value to all academic levels of the university is a good collection of basic reference materials-including dictionaries and encyclopedias of religion, concordances, handbooks and yearbooks, bibliographies, indexes, and abstracting tools. These 
are essential works without which any university library is severely handicapped. Second, the collection should include broad coverage in the history of religions as well as biographies of important religious personalities. Such items are of value not only to the study of religion per se, but also to an understanding of man's cultural and intellectual development. Next, the library should include the essential books of faith of the major religions in their various versionssuch as the Bible, the Koran, the Analects of Confucius, the Bhagavad-Gita, the Book of Mormon, etc. Closely related to these may be certain exegetical works as well as classics of religious devotion. A fourth category is made up of a variety of general works such as those dealing with particular doctrinal beliefs or movements, comparative religion, the writings of important religious leaders, and books dealing with the practical aspects of religion in contemporary life. Finally, there should be provision of some religious periodical literature both for general interest reading and serious study and scholarship. A range of contemporary views of the three major Western faiths, for instance, is provided by America for Roman Catholicism, Commentary for Judaism, and The Christian Century for Protestantism. Of more scholarly value are such titles as the Journal of Biblical Literature, Church History, The Journal of Church and State, Journal of Religion and Health, and the Journal for the Scientific Study of Religion. The selection of scholarly journals depends largely upon their need for courses of study or for research interests of faculty members.

The levels of collecting in the area of religious literature will naturally vary greatly among institutions, depending upon factors already presented. Policy statements from several university libraries suggest levels used in book collecting. The University of Illinois state- ment ${ }^{19}$ sets forth the following four: (1) general, which attempts "to introduce and define the subject, and to indicate the varieties of information which are available elsewhere"; (2) instructional, described as "a good working collection designed to meet all instructional needs"; (3) comprehensive research, containing "all current publications of research value and such retrospective publications as are deemed desirable by the faculty and are procurable"; and (4) exhaustive research, "including as far as possible all publications of research value, including marginal materials such as manuscripts, archives, and ephemera." With regard to religion, the coverage at Illinois is at the first level, with assignment of primary responsibility for selection to the department of education. Three levels of coverage are specified by the Louisiana State University library:20 (1) college collections, (2) research collections, and (3) pre-eminence or virtually complete collections in a very few subjects. The University of New Mexico outlines four degrees of collection: ${ }^{21}$ (1) "a limited, basic collection .... on subjects not related to the curriculum"; (2) "a teaching collection .... (to) contain reference works, monographs, and periodicals"; (3) "a research collection to support master's, doctor's and the faculty's research"; and (4) "a complete collection (including) everything on a subject in all editions, translations, and languages."

Keeping in mind the factors discussed earlier, these categories may be related to the acquisition of religious books by a state university in the following overall framework. Selecting at the first or general level might readily be justified in all institutions. Collecting at the instructional and research levels depends directly upon what is being offered in

\footnotetext{
10 University of Illinois, "Acquisition Policy Statement" (Urbana, February 1959), pp. 2, 3. Mimeograph.

${ }^{20}$ Louisiana State University and Agricultural and Mechanical College, "Book Selection Policies and Procedures" (Baton Rouge, 1953), p. 1. Mimeograph. 21 University of New Mexico, "Acquisitions Policy" (1957). Mimeograph.
} 
the institution's teaching and research program, as well as on the nature of the existing collection. Acquisition in the exhaustive sense would be undertaken only where regional historical or cultural factors are completely dependent upon the university exercising this responsibility, or where a department of religion exists through which advanced degrees are offered.

\section{RESPONSIBILITY FOR SELECTING}

\section{ReLigious Books}

The question logically arises, "Who should be responsible for selecting religious books?" Here the pattern is basically parallel to selection responsibilities in other subjects.

First, the faculty shares largely in this responsibility. Where there is a department of religion, selection of materials in this field falls primarily within its jurisdiction. Where such a department does not exist, responsibility might officially be delegated to another department (as cited already for the University of Illinois), or generally distributed to several other departments within which courses dealing with religion are offered.

Second, various members of the library's professional staff may function as book selectors in religion. It would normally be expected that the staff of the reference department as well as departmental libraries-e.g., music and art -would choose religious works of importance for their collections. If the acquisitions department has a core of bibliographers engaged in book selection, the concern for general religious materials might be assigned to one or more of these. Furthermore, the head of the acquisitions department, upon whom considerable responsibility for the over-all growth of the collection often rests, would also function in selecting books on religion; this would be especially true both in balancing the collection and in maintaining already existing strengths in the library's holdings.

Finally, the users of the library besides the faculty, including the student body and in some cases the public at large, would play a part in the selection process mainly through the requests which they make for specific materials. While this group does not figure as prominently in this function as the members of the library staff, it cannot be ignored in the acquisition program.

\section{Attitudes and Practices of Faculty Members}

In order to provide some firsthand data on this subject, seven faculty members on the Berkeley campus of the University of California were interviewed regarding their attitudes and practices in the selection of religious books. In each case these persons, chosen from the departments of anthropology, classics, English, history, Near Eastern languages, philosophy, and sociology, teach courses related to religion within their respective academic fields. Five points of discussion served as the basis for the interviews: (1) level of selection, (2) responsibility for selection, (3) sources from which selections are made, (4) time spent in selection, and (5) attitude toward selection of religious materials as compared with those in other academic fields.

All persons interviewed assumed without question that religious books at the general and instructional levels should be acquired. Beyond this, it was felt that research materials should be selected primarily where they support the work of graduate students and faculty members, or where they complement other materials on the same level in closely related subject fields. For example, an opinion was expressed that advanced work in Milton requires a broad collection of religious works at the research level for Milton's period. Likewise, it was pointed out that historical research on the ages of the Renaissance and Reformation necessitates many items in religious philosophy and theology beyond the general or instruc- 
tional levels. There was general agreement that a strong case would have to be made to justify exhaustive collecting of religious materials. The main reasons cited to warrant such activity were the responsibility to support advanced research work and the obligation to maintain at this level existing collections already in the library.

Opinions regarding responsibility for selecting religious books varied widely among those interviewed. One faculty member, for instance, felt keenly that selection of materials beyond the general or introductory level should be almost entirely the prerogative of the teaching staff; another (German-trained) felt strongly that full responsibility for selection should be assigned to a core of specialized bibliographers within the library, and that faculty members should serve only in an advisory or consultant capacity. Between these two points of view a compromise opinion was offered that department librarians should regularly present suggestions on which faculty members would make final decisions. In general, the majority believed that the role of faculty members is to use their specialized knowledge in particular subject areas to build upon the basic work of selection performed by members of the library staff.

Considerable agreement was expressed with regard to the sources from which selections are made. Those most largely relied upon are publishers' and dealers' catalogs, book reviews, and lists of books received in scholarly journals. Only one person reported going through specifically religious book catalogs; in general, no distinctions were made in the sources for selection of religious materials from those of other subject fields.

The over-all time spent in book selection ranged on a weekly basis from "no specific amount" to about ten hours; the average appeared to be between one and two hours. Of this, however, none of those interviewed indicated any specific amount for selection of books on religion.

Finally, in discussing attitudes toward the selection of religious books and the question of whether they might be considered controversial in a state-supported, non-sectarian institution, there was unanimity of opinion that such materials were selected primarily on the basis of their scholarly value and the contribution they make to the history of ideas and the cultural development of mankind. Only one person expressed specific concern that balanced points of view be represented especially in polemical works; another, however, felt that works on certain selected subjects or by prominent authors ought to be selected regardless of the particular position which they represent. The outlook of the academic community was thought to be sufficiently broad that the acquisition of religious books would be accepted without controversy. With regard to their selection, therefore, consideration beyond that given to books in other subject fields was generally considered to be unnecessary.

\section{Conclusion}

This paper has stemmed from the realization that state university libraries are involved in selecting and collecting religious books; it is further based upon the premise that there is a place for such materials in a tax-supported institution of higher learning.

Finding little in the literature of librarianship dealing directly with this subject, the study has endeavored to examine the factors involved in the selection of religious materials for a state university library, to consider what kinds of literature may justifiably be selected, and to decide who should be involved in the process of selection.

It is hoped that the information and ideas set forth are of sufficient value to contribute both to the formation of a policy statement and to the acquisition process for religious literature in the state university library. 